\title{
Short Communication \\ First record of visual displays in Scinax cardosoi (Anura: Hylidae)
}

\author{
Matheus de Toledo Moroti, ${ }^{1}$ Mariana Pedrozo, ${ }^{2}$ Guilherme Sestito, ${ }^{1}$ and Diego José Santana ${ }^{1}$ \\ ${ }^{1}$ Laboratório de Zoologia, Instituto de Biociências, Universidade Federal de Mato Grosso do Sul, Cidade Universitária, $79002-$ \\ 970, Campo Grande, MS, Brazil. E-mail: mmoroti@gmail.com. \\ ${ }^{2}$ Instituto de Ciências Exatas e Biológicas, Universidade Federal de Ouro Preto, Rua Quatro 786, 35400-000, Ouro Preto, MG, \\ Brazil.
}

Keywords: Atlantic Forest, ethology, territorial defense, treefrog, visual communication.

Palavras-chave: comunicação visual, defesa de território, etologia, Mata Atlântica, perereca.

Anurans have a variety of social behaviors (Wells 1977). Acoustic communication is the best documented, occurring in most anuran species (Hartmann et al. 2005). Anuran visual communication has received more attention following the reviews by Hödl and Amézquita (2001) and Hartmann et al. (2005). Several types of visual signals have been described in anuran species (e.g., Bertoluci 2002, Hartmann et al. 2005, Giasson and Haddad 2006, Toledo et al. 2007, Caldwell et al. 2010, Barros and Feio 2011, Lipinski et al. 2012, Caldart et al. 2014, Furtado et al. 2017).

Visual signaling is a complementary or alternate form of communication in most anurans depending on the social context (Amézquita and Hödl 2004). It is primarily associated with elements of reproductive behavior, such as courtship and aggressive interactions between conspecific males (Hödl and Amézquita 2001).

Received 31 May 2017

Accepted 25 October 2017

Distributed December 2017
Thus, anuran visual communication may have an important social function that probably is more significant than currently recognized (Caldart et al. 2014).

Visual signals in anurans are present in a number of species and families (Furtado et al. 2017), suggesting that this communication system may have evolved independently on multiple occasions (Hödl and Amézquita 2001). Within Scinax Wagler, 1830, visual signals are recorded for four species-Scinax eurydice (Bokermann, 1968), S. fuscomarginatus (Lutz, 1925), S. maracaya (Cardoso and Sazima, 1980), and S. nasicus (Cope, 1862). Two types of visual displays occur in the genus. Limb-lifting is documented for the four species (S. eurydice, $S$. fuscomarginatus, S. maracaya, S. nasicus) and leg-kicking only for one species ( $S$. eurydice; Hartmann et al. 2005, Toledo and Haddad 2005, Barros and Feio 2011, Furtado et al. 2017).

Scinax cardosoi (Carvalho-e-Silva and Peixoto, 1991) occurs in Atlantic Forest fragments in the states of Minas Gerais, Espírito Santo, Rio de Janeiro, and São Paulo (Moroti et al. 2017), southeastern Brazil. This nocturnal 
species uses temporary ponds along the forest edge for breeding. Males vocalize next to one another from perches on shrub vegetation $(\sim 20$ $30 \mathrm{~cm}$ above ground) (Moroti et al. 2017). Despite its range over an enormous area in southeastern Brazil, the records of its populations are disjunct, and there is little information on the ecology and behavior of $S$. cardosoi. Here, we describe the visual displays observed in a population of $S$. cardosoi in an Atlantic Forest fragment in southeastern Brazil.

The observations were carried out at the Parque Natural Municipal Augusto Ruschi (PNMAR), municipality of São José dos Campos, state of São Paulo, Brazil, on 17 January 2016. The adult Scinax cardosoi were found calling from a temporary pond in an area of secondary forest $\left(23.0714^{\circ} \mathrm{S}, 45.9313^{\circ} \mathrm{W}\right.$, WGS-84). Several males were vocalizing from scattered, shrubby vegetation in the same ephemeral pond. A total of 1:30 hr of observations was made before the sunrise, between 5:00 $\mathrm{h}$ and 6:30 h. The air temperature and air humidity were measured with a thermohygrometer (Instrutemp ITHT 2250) during the observations. The average temperature varied from 19.7$21.8^{\circ} \mathrm{C}$ and the relative air humidity from $90-94 \%$.

Our observations followed the ad libitum method (Lehner 1996). The same observer (MTM) used a white-light lantern and was always at least $2 \mathrm{~m}$ away from the focal individuals; this distance did not seem to interfere in the interactions between the frogs. We observed nine individuals ( 7 males, 2 females), each for $10 \mathrm{~min}$. The visual behavior of three males was recorded with a digital camera (Nikon P600) and classified according to Hartmann et al. (2005). Two males were collected as voucher specimens (collection permits SISBio 54493-2) and deposited in the herpetological collection of the Universidade Federal de Mato Grosso do Sul (ZUFMS-AMP 5627-5628).

Neither of the two females displayed any visual behavior. The males engaged in two kinds of visual displays. The first, limb-lifting, was observed in all male frogs; four of the frogs were in the presence of conspecific males, whereas three were not. This signal consists of moving one or more of the hind or forelimbs rapidly up and down without extending the limbs. In both contexts (i.e., with or without conspecifics), the frogs touched the substrate with limbs (Figure 1). The second behavior, leg-kicking, was observed in two males when there was another male frog nearby. The male that was calling stretched his right hind limb back to hit its conspecific. Because only one individual vocalized, it seems likely that the male that was kicked might have been a satellite male (Figure 2). The presumed satellite male maintained his position for a minute, and then jumped to other vegetation right. Leg-kicking behavior only occurred in the presence of another male, thereby suggesting that it is an aggressive behavior.

Visual signals are more commonly associated with diurnal anurans, owing mainly to their signal transmission facility and perception (Hödl and Amézquita 2001). However, optimal illumination may vary among species; many anurans are active only at low light intensities (Hartmann et al. 2005). When the white light of our lantern was focused on individual frogs, the males performing visual displays ceased this behavior, but did not stop calling. When the light was not focused on individuals, they resumed their visual behavior displays. We found that anuran visual displays were inversely correlated with the light intensity. It will be important to test whether the rate of visual signaling in anurans with nocturnal habits decreases with increasing light, or whether this is only in response to intense white light.

The use of visual cues in anurans usually occurs when a resident male sees a conspecific (Lindquist and Hetherington 1998). In an experiment using mirrors, Furtado and Nomura (2014) observed that Boana albomarginata (Spix, 1824) altered its rate of emission of acoustic signals in the presence of a possible intruder male, but did not change the rate of visual displays, thereby this suggesting that the latter is not involved in communication and is a "displaced 

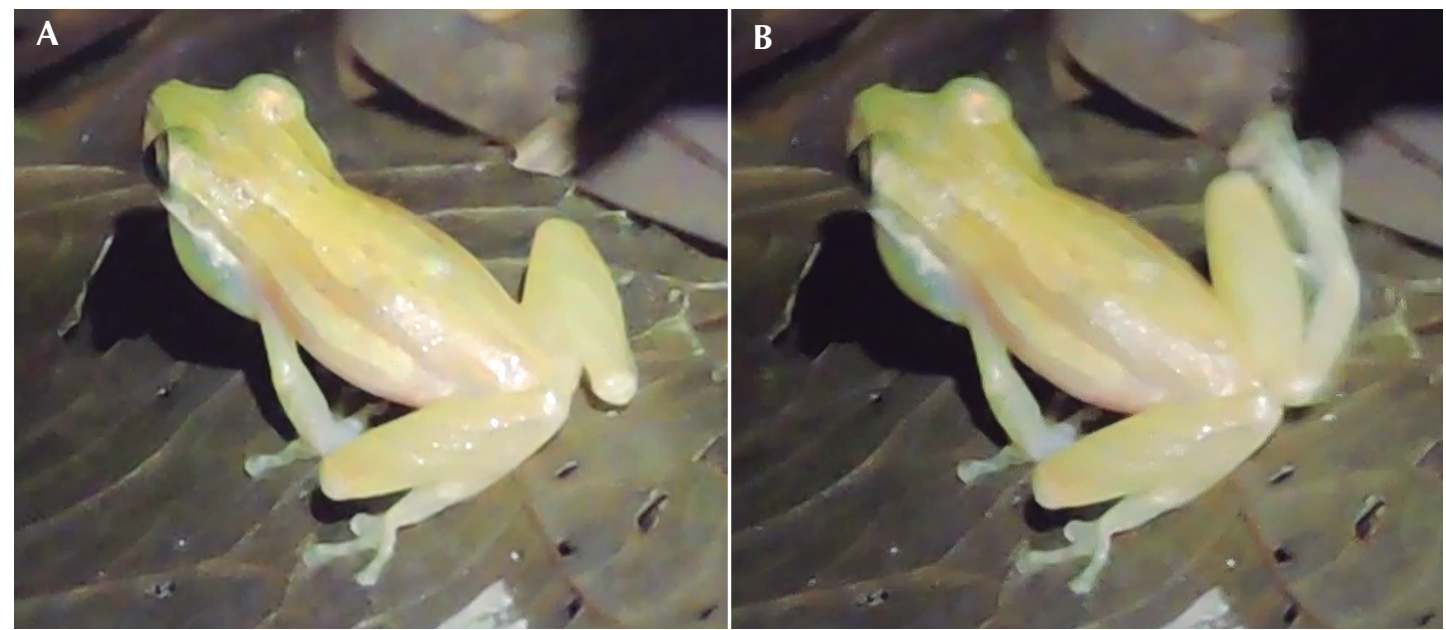

Figure 1. (A) A male Scinax cardosoi in the Parque Natural Municipal Augusto Ruschi, municipality of São José dos Campos, state of São Paulo, southeastern Brazil. (B) Limb-lifting observed in individuals of S. cardosoi. The signal consisted of rapid up and down movements of one or more limbs that are not extended.

activity" in this species (Furtado and Nomura 2014). Anurans also use seismic signals to communicate; in some cases, this may establish patterns of spacing in the chorus of the males
(Narins 1990), as suggested in a study of an aboreal frog, Agalychnis callidryas (Cope, 1862) by Caldwell et al. (2010). Combined, visual and vibrational signaling compose a bimodal signal,

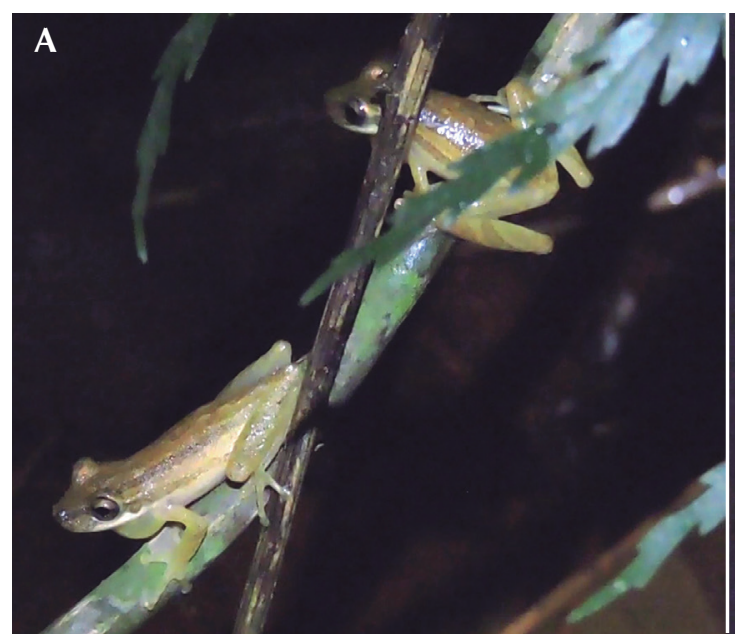

B

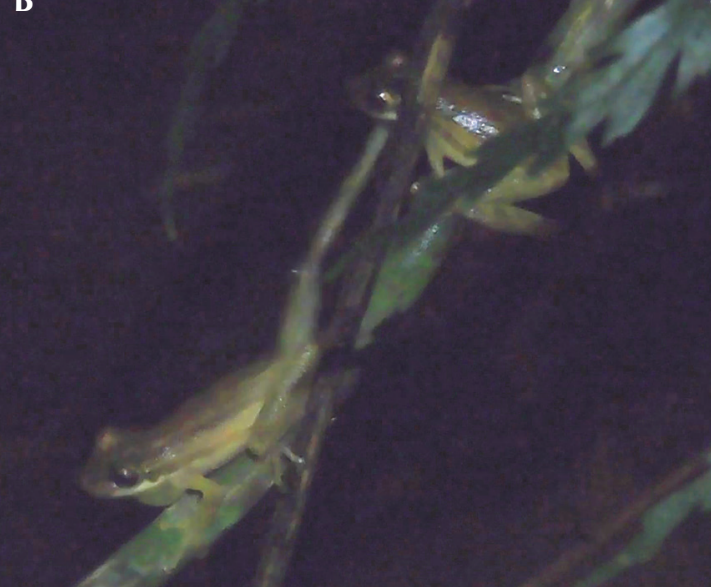

Figure 2. (A) Two male Scinax cardosoi (ZUFMS 5627-5628); the left male displayed "leg kicking" to push the other male away. The latter did not vocalize, whereas the former did; thus, the silent male may have been a satellite. (B) The most active male stretched his right leg back to hit other male, which remained in the same position for a minute, jumping to other vegetation right after. In our observations, the leg kicking behavior was only displayed in the imminence of another male, suggesting aggressive behavior. 
because male A. callidryas do not respond to visual stimuli only (Caldwell et al. 2010).

Furtado et al. (2017) observed visual displays associated with agonistic interactions in three hylid species [Boana raniceps (Cope, 1862), Dendropsophus nanus (Boulenger, 1889), and Lysapsus limellum Cope, 1862] and found that the visual stimulus of an intruder male in the territory of the resident male does not affect the rate of visual signaling. In our study, limb-lifting behavior in Scinax cardosoi was reported in both the presence and absence of other conspecific males, as observed in other studies (Furtado and Nomura 2014, Furtado et al. 2017). However, Hartmann et al. (2005) verified that in the absence of another vocalizing male, individual Vitreorana uranoscopa (Müller, 1924) ceased limb-lifting behavior but continued to vocalize. Possibly, behavior differs among species depending on the type of habitat they use, their evolutionary history, the availability of light, and the noise of the environment.

The visual displays observed in Scinax cardosoi (limb-lifting and leg-kicking) are documented in some of its congeners (Hartmann et al. 2005, Toledo and Haddad 2005, Barros and Feio 2011, R. Furtado pers. obs.). However, our study shows that leg-kicking may be used in intraspecific aggressive interactions in this species. We documented that display of visual signals in $S$. cardosoi changes with light intensity, because such displays cease when the lantern light is focused directly on an individual; nevertheless, the frog continues to vocalize. Thus, our study provides new insights on visual communication in Scinax, while raising further research questions to explore.

Acknowledgments.-We are grateful to Secretaria do Meio Ambiente de São José dos Campos for the study permit in the area of Parque Natural Municipal Augusto Ruschi. We thank Linda Trueb, Rafaela Granzotti and anonymous referees for critical discussions of the ideas presented in this manuscript. MTM and GAS were supported by CAPES for this research.

\section{References}

Amézquita, A. and W. Hödl. 2004. How, when, and where to perform visual displays: the case of the Amazonian frog Hyla parviceps. Herpetologica 60: 420-429.

Barros, A. B. and R. N. Feio. 2011. Visual communication in Scinax maracaya (Cardoso \& Sazima, 1980) (Anura: Hylidae) at the Serra da Canastra National Park, southeastern Brazil. Herpetology Notes 4: 103104.

Bertoluci, J. 2002. Pedal luring in the leaf-frog Phyllomedusa burmeisteri (Anura, Hylidae, Phyllomedusinae). Phyllomedusa 1: 93-95.

Caldart, V. M., S. Iop, and S. Z. Cechin. 2014. Social interactions in a Neotropical stream frog reveal a complex repertoire of visual signals and the use of multimodal communication. Behaviour 151: 719-739.

Caldwell, M. S., G. R. Johnston, J. G. McDaniel, and K. M. Warkentin. 2010. Vibrational signaling in the agonistic interactions of red-eyed treefrogs. Current Biology 20: $1012-1017$.

Furtado, R. and F. Nomura. 2014. Visual signals or displacement activities? The function of visual displays in agonistic interactions in nocturnal tree frogs. Acta Ethologica 17: 9-14.

Furtado R., R. Márquez, and S. M. Hartz. 2017. In front of a mirror: visual displays may not be aggressive signals in nocturnal tree frogs. Journal of Natural History 51: $443-454$.

Giasson, L. O. M. and C. F. B. Haddad. 2006. Social interactions in Hypsiboas albomarginatus (Anura: Hylidae) and the significance of acoustic and visual signals. Journal of Herpetology 40: 171-180.

Hartmann, M. T., L. O. M. Giasson, P. A. Hartmann, and C. F. B. Haddad. 2005. Visual communication in Brazilian species of anurans from the Atlantic forest. Journal of Natural History 39: 1675-1685.

Hödl, W. and A. Amézquita. 2001. Visual signaling in anuran amphibians. Pp. 121-141 in M. J. Ryan (ed.), Anuran Communication. Washington. Smithsonian Institution Press.

Lehner, P. N. (ed). 1996. Handbook of EthologicalMethods. Cambridge. Cambridge University Press.694 pp.

Lindquist, E. D. and T. E. Hetherington. 1998. Semaphoring in an earless frog: the origin of a novel visual signal. Animal Cognition 1: 83-87. 
Lipinski, V. M., V. M. Caldart, and S. Iop. 2012. Visual communication in Hypsiboas curupi (Anura: Hylidae) at Parque Estadual do Turvo, southern Brazil. Phyllomedusa 11: 71-74.

Moroti, M. T., J. A. Ferreira Neto, A. C. Santos, C. P. Soares, and I. F. Machado. 2017. Amphibia, Anura, Hylidae, Scinax cardosoi (Carvalho-e-Silva \& Peixoto, 1991): distribution extension and new state record for São Paulo, Brazil. Check List 13: 2042.

Narins, P. M. 1990. Seismic communication in anuran amphibians. Bioscience 40: 268-274.
Toledo, L. F. and C. F. B. Haddad. 2005. Reproductive biology of Scinax fuscomarginatus (Anura, Hylidae) in south-eastern Brazil. Journal of Natural History 39: 3029-3037.

Toledo, L. F., O. G. S. Araújo, L. D. Guimarães, R. Lingnau, and C. F. B. Haddad. 2007. Visual and acoustic signaling in three species of Brazilian nocturnal tree frogs (Anura, Hylidae). Phyllomedusa 6: 61-68.

Wells, K. D. 1977. The social behavior of anuran amphibians. Animal Behaviour 25: 666-693.

Editor: Jaime Bertoluci 